\title{
Oxidation of polycrystalline Ni studied by spectromicroscopy: Phase separation in the early stages of crystallite growth
}

Article

Accepted Version

Cornish, A., Eralp, T., Shavorskiy, A., Bennett, R. A., Held, G. F. K., Cavill, S.A., Potenza, A., Marchetto, H. and Dhesi, S.S. (2010) Oxidation of polycrystalline Ni studied by spectromicroscopy: Phase separation in the early stages of crystallite growth. Physical Review B, 81 (8). 085403. ISSN 1098-0121 doi: https://doi.org/10.1103/PhysRevB.81.085403 Available at https://centaur.reading.ac.uk/15532/

It is advisable to refer to the publisher's version if you intend to cite from the work. See Guidance on citing.

To link to this article DOI: http://dx.doi.org/10.1103/PhysRevB.81.085403

Publisher: American Physical Society

All outputs in CentAUR are protected by Intellectual Property Rights law, including copyright law. Copyright and IPR is retained by the creators or other copyright holders. Terms and conditions for use of this material are defined in the End User Agreement. 


\section{CentAUR}

Central Archive at the University of Reading

Reading's research outputs online 


\title{
The oxidation of polycrystalline Ni studied by spectromicroscopy: phase separation in the early stages of crystallite growth
}

\author{
A. Cornish, T. Eralp, A. Shavorskiy, R. A. Bennett, and G. Held* \\ University of Reading, Department of Chemistry, Reading, RG6 6AD, UK \\ S. A. Cavill, A. Potenza, H. Marchetto, and S. S. Dhesi \\ Diamond Light Source, Chilton, Didcot, OX11 ODE, UK
}

(Dated: January 10, 2010)

\begin{abstract}
Low-energy and photoemission electron microscopy (LEEM/PEEM) enables the determination of facet planes of polycrystalline surfaces and the study of their chemical composition at the sub$\mu \mathrm{m}$ scale. Using these techniques the early oxidation stages of nickel were studied. After exposing the surface to $20 \mathrm{~L}$ of oxygen at $373 \mathrm{~K}$ a uniform layer of chemisorbed oxygen was found on all facets. After oxygen exposure at $473-673 \mathrm{~K}$, small $\mathrm{NiO}$ crystallites are formed on all facets but not in vicinity of all grain boundaries. The crystallites are separated by areas of bare Ni without significant oxygen coverage.

PACS numbers: 68.35.Dv, 68.37.Nq, 68.47.Gh
\end{abstract}

*Electronic address: g.held@reading.ac.uk 


\section{INTRODUCTION}

Recent advances in photoemission and low-energy electron microscopy (PEEM and LEEM) [1,2]) make it possible to apply electron spectroscopy and diffraction techniques to surface features of only a few $\mu \mathrm{m}$ in diameter. Therefore, well established surface science techniques, such as X-ray photoelectron spectroscopy (XPS), near-edge X-ray absorption fine structure (NEXAFS) spectroscopy, or low-energy electron diffraction (LEED), can be applied to individual crystallites of polycrystalline materials in order to retrieve structural and quantitative chemical information at a level that was so far only possible in single crystal studies. Here we present a study of the early oxidation stages of polycrystalline nickel. The use of PEEM and LEEM enables the simultaneous characterization of several surface facets under identical conditions and provides new insight in the growth mechanism of the oxide layer.

$\mathrm{NiO}$ is the most common anti-ferromagnetic component in antiferromagnetic/ferromagnetic compound materials [3, 4], where the film homogeneity is of extreme importance. The oxidation of Ni has, therefore, been studied over many years both on single crystal and polycrystalline samples [5-23]. In order to describe the early stages a three-step mechanism has been proposed by Holloway and Hudson [9, 10] for $\mathrm{Ni}\{111\}$ and $\{100\}$ : the first step involves fast dissociative chemisorption of oxygen; secondly, $\mathrm{NiO}$ clusters nucleate and grow forming a thin $\mathrm{NiO}$ film; the last step involves slow thickening of the $\mathrm{NiO}$ film, which is limited by the diffusion of nickel cations through the oxide film [11]. Later XPS and scanning tunnelling microscopy 
(STM) studies support this mechanism. A single metallic Ni $2 \mathrm{p}_{3 / 2}$ photoemission peak of $\mathrm{Ni}\{111\}$ indicates that oxygen only chemisorbs for exposures up to $10 \mathrm{~L}\left(1 \mathrm{~L}=10^{-6}\right.$ Torr.s $)$ at room temperature, whereas for higher exposures additional XPS peaks indicate the formation of $\mathrm{NiO}[12,13]$. STM images reveal that the oxide layer on $\mathrm{Ni}\{111\}$ and $\mathrm{Ni}\{100\}$ nucleates at step edges and grows into the terraces [14-16]. Chen et al. [5, 17] identified two distinct temperature regimes, below $500-600 \mathrm{~K}$ a 2-3 layers thick oxide film is formed, which wets and passivates the Ni surface; at higher temperatures the oxide film breaks up into three-dimensional crystallites. Similar effects have been reported recently for polycrystalline Ni samples [8], however no microscopic information is available about island size and distribution or the involvement of grain boundaries in the latter case.

In this study PEEM and LEEM were used for real time imaging with a lateral resolution in the $\mathrm{nm}$ range enabling the study of the growth kinetics of oxide formation for several facets and their boundaries simultaneously [18]. In addition, the observed features can be characterized structurally and chemically using LEED and NEXAFS, respectively. The latter clearly shows that oxygen is homogeneously chemisorbed in the low-temperature regime whereas at high temperatures phase separation occurs into NiO clusters, which are separated by bare Ni without significant oxygen coverage.

\section{EXPERIMENTAL PROCEDURES}

The experiments were carried out at the nanoscience beamline I06 of Diamond Light Source, UK, which provides soft X-ray radiation of variable polarization and is equipped with an Elmitec energy-dispersive LEEM/PEEM 
instrument with a maximum lateral resolution of $20 \mathrm{~nm}$ and an energy resolution of $0.3 \mathrm{eV}[1,2]$. The instrument was used in several different modes: PEEM, spatially resolved (230 nm at $40 \mu \mathrm{m}$ field of view) detection of photo or secondary electrons; LEEM, spatially resolved (>40 nm) detection of reflected electrons emitted from an internal electron gun; micro-spot LEED and XPS, diffraction pattern or photoemission, respectively, from a selected area (typically $2 \mu \mathrm{m}$ ). LEEM images were recorded in the mirror electron microscopy (MEM) mode, using electrons with negative kinetic energies in the range 0 to $-2 \mathrm{eV}$. The contrast in this mode is due to local workfunction differences.

Spatially resolved NEXAFS spectra at the oxygen K edge were measured by recording PEEM images of low kinetic-energy secondary electrons (0$3 \mathrm{eV}$ ) while the photon energy was scanned in steps of $0.1 \mathrm{eV}$ between 520 and $550 \mathrm{eV}$. Circularly polarized synchrotron radiation - averaging over polarization directions parallel and perpendicular to the surface - was used in order to minimize orientation-related effects. In order to ensure homogeneous illumination of large field of view images (40 or $80 \mu \mathrm{m}$ ) the center of the synchrotron radiation beam was moved outside the field of view so that the image area was illuminated by stray light. The integrated pixel intensities of morphological features were extracted from each image, normalized with respect to the photon flux, $I_{0}$, and plotted vs photon energy. Lateral drifts of the beam caused small artificial features in the NEXAFS spectra despite normalization with respect to $I_{0}$.

The polycrystalline nickel sample (purity 99.99\%) was polished with abra- 
sive paper and diamond paste down to $1-2 \mu \mathrm{m}$ followed by electro-polishing. The sample was cleaned in ultra-high vacuum by Ar ion sputtering and annealing to $1200 \mathrm{~K}$ several times. No change in the shapes of individual grains could be detected during the course of the experiments. The temperature was measured through a $\mathrm{K}$-type thermocouple attached to the sample. Micro-spot C 1s XPS spectra were recorded on a regular basis to check carbonacious contamination of the sample surface.

\section{RESULTS AND DISCUSSION}

Most of the experiments presented here concentrated on a representative surface area of about $500 \times 750 \mu \mathrm{m}^{2}$. Figure 1 (a) shows a map compiled from overlapping LEEM images(field of view $80 \mu \mathrm{m}$ ). The map shows the boundaries between five different grains ( $\mathrm{Ni}$ crystallites), as indicated in Figure 1(b), and other surface features greater than about $50 \mathrm{~nm}$, such as scratch marks from polishing. Typical grain diameters were in the region of $100-500 \mu \mathrm{m}$ throughout the surface. For each of the grains shown in Figure 1(a), micro-spot LEED was used to determine the surface orientation. Examples of the diffraction patterns are also shown in Figure 1(b); distortions and weak extra features are due to small tilts of the facets with respect the macroscopic surface normal and residual gas adsorption, respectively. The facet terminations are $\{111\},\{100\}$, $\{110\}$, and a more complicated stepped surface whose termination could not be determined unambiguously. Elongated and/or split diffraction spots indicate that the step density on most grain sur- 
faces is higher than on carefully orientated single crystals, i.e. they are closely vicinal rather than perfect low-index surfaces. Spatially resolved NEXAFS focussed on two regions with three different adjacent facets each, which are indicated by circles in Figure 1(b). This way, the oxidation of several facets could be monitored simultaneously.

Changes in the surface morphology during oxygen adsorption were monitored with LEEM and PEEM for constant temperatures between $373 \mathrm{~K}$ and $673 \mathrm{~K}$ while the sample was exposed to several $\mathrm{L}$ at $1 \times 10^{-8}$ mbar. At $373 \mathrm{~K}$ a homogeneous increase in the workfunction on each facet was observed in LEEM indicating the formation of a uniform oxide layer. During oxygen exposure at temperatures between $473 \mathrm{~K}$ and $673 \mathrm{~K}$ spots appear in the images, which are of variable size and density, depending on the temperature and facet termination. The X-PEEM images in Figure 2(b) (20 L at 373K) and 3(b) (30 L at $673 \mathrm{~K}$ ) show typical examples of the two phases in region 1 containing adjacent stepped, $\{110\}$ and $\{100\}$ facets (see Figure 1).

After oxygen adsorption at $373 \mathrm{~K}$ the spatially resolved NEXAFS spectra from all facets, Figure 2(a), show very similar features at 529 and around $536 \mathrm{eV}$, which are typical for chemisorbed oxygen on Ni single crystal surfaces [19-21]. Unlike in the earlier studies all resonances are present in these spectra because circularly polarized radiation is used. The bright spots seen in the X-PEEM images Figure 3(b) and (c) after exposing the surface to $30 \mathrm{~L}$ of oxygen at $673 \mathrm{~K}$ indicate the growth of $\mathrm{NiO}$ crystallites. The corresponding NEXAFS spectra for the crystallite spots and the areas between the crystallites on each facet are shown in Figure 3(a). They are very simi- 
lar to spectra obtained from bulk $\mathrm{NiO}$ or oxidized single crystal $\mathrm{Ni}$ surfaces $[19,20,22]$ with pronounced $3 e_{g}$ and $3 a_{1 g}$ single electron excitations at $531 \mathrm{eV}$ and $539.5 \mathrm{eV}$, respectively, and a peak due to multi-electron configuration interactions around $536 \mathrm{eV}$. The interstitial areas between the crystallites, on the other hand, show only weak features caused by drifts of the synchrotron beam but no signal associated with $\mathrm{NiO}$. The oxygen signal in these spectra is near the noise level (equivalent to less than 0.05 ML O). They can, therefore, be used to normalize the spectra of nearby crystallites in order to remove features due to beam drift. After this extra normalization step the spectra of crystallites on the same facet show the same intensity ratios. There are, however, characteristic differences in the relative heights of the spectral features between different facets. On the $\{111\}$ and $\{100\}$ facets the ratio between the $3 e_{g}$ and the $3 a_{1 g}$ resonance peaks is almost $1: 2$ whereas it is close to $1: 1$ on the $\{110\}$ facet. This is most likely caused by different crystallite orientations and, hence, different cross sections for the NEXAFS excitations. Because of the grazing incidence geometry circular polarization does not average out different azimuthal orientations.

There are also characteristic differences in the average size and density of crystallites on different facets. E.g., on the stepped facet the crystallites are on average about twice as large $(\approx 1 \mu \mathrm{m}$ in diameter $)$ as on the $\{111\}$ facet. Note, that the $\mathrm{X}$-PEEM images from region 1, Figure 3(b), were recorded several hours after those from region 2, Figure 3(c). During this time ripening of the crystallites has occurred which accounts for the larger crystallite size on all facets in Figure 3(b). Fast diffusion of individual oxygen atoms across the bare Ni re- 
gions, which is necessary for this ripening process, would not lead to a signal above the detection limit of our experiment (0.05 ML). Earlier STM work found that the crystallites nucleate on step edges [16] but the step densities (typically $>10 \mu \mathrm{m}^{-1}$ ) are much higher than the crystallite density (typically $<0.5 \mu \mathrm{m}^{-1}$ ). Therefore this cannot be used to explain differences between facets. A more likely explanation is that this is caused by differences in the diffusion of oxygen atoms.

Figure 4 shows MEM-LEEM images of a sample area outside the map of Figure 1, which were recorded during exposure to oxygen at $1 \times 10^{-8}$ mbar at $573 \mathrm{~K}$ and $673 \mathrm{~K}$. NiO appears dark because of its higher workfunction compared to metallic Ni. The images clearly show fewer $\mathrm{NiO}$ crystallites with larger diameters for the higher temperature on all three facets seen in the images (the orientations of these facets were not identified by micro-spot LEED). This is a strong indication that ripening is indeed an important feature of the growth process. The MEM imaging mode has the advantage of fast data acquisition and high contrast, however small features appear bigger that their actual size. Therefore, the apparent crystallite size is only a qualitative measure.

The fact that the $\mathrm{NiO}$ crystallites develop at higher temperatures on all facets indicates that this is the thermodynamically favored surface configuration of oxygen on $\mathrm{Ni}$. Chemisorbed oxygen is a metastable configuration, which is kinetically hindered, most likely by the slow diffusion of Ni ions at lower temperatures. An earlier study by Wang et al. has shown that $\mathrm{NiO}$ begins to form at $350 \mathrm{~K}$ after longer exposures of $80 \mathrm{~L}$ [23]. It is 
surprising though that the area between the crystallites does not show any significant oxygen coverage. Obviously, a surface consisting of clean Ni and $\mathrm{NiO}$ crystallites is lower in energy than coexisting chemisorbed oxygen and $\mathrm{NiO}$, which is observed at lower temperatures [16]. Previous research showed that oxidation proceeds faster on polycrystalline than on single crystal $\mathrm{Ni}$ surfaces. This was attributed to the grain boundaries facilitating the transport of Ni cations [8]. Our data show that this is not generally true. The grain boundaries running between the stepped and the $\{110\}$ facet and between the stepped and the $\{100\}$ facet contain no oxide crystallites. Even the regions directly adjacent to these facet boundaries appear devoid of crystallites, particularly the $\{110\}$ facet where no oxide islands are present within $4 \mu \mathrm{m}$ of the grain boundary. Oxide crystallites are observed, however, on the grain boundary between the $\{110\}$ and $\{100\}$ facets. A likely reason is that different types of stress-induced lattice distortions cause unfavorably high lattice mismatches at certain types of grain boundaries. Closer inspection of Figure 4 shows that the growth on or near grain boundaries also strongly depends on the temperature. The boundary between facets 2 and 3 in Figure 4 is only significantly decorated after exposure at $673 \mathrm{~K}$ and the near-boundary region of facet 3 shows a very low crystallite density. At $573 \mathrm{~K}$, however, no depletion of crystallites is seen near this boundary and only a small number of crystallites grows on the boundary. In general, the depletion of near-boundary regions seems to occur only at higher temperatures. At lower temperatures, the nucleation and growth of crystallites takes place in these regions despite being thermodynamically un- 


\section{favourable because diffusion is too slow.}

\section{SUMMARY}

In summary, we used PEEM and LEEM to identify the surface facets of polycrystalline $\mathrm{Ni}$ and to study the early stages of $\mathrm{NiO}$ growth on several facets simultaneously. For oxygen exposure at $473 \mathrm{~K}$ and higher, spatially resolved NEXAFS spectra clearly identify $\mathrm{NiO}$ crystallites with diameters in the $1 \mu \mathrm{m}$ range and areas of clean Ni surface between them. For lower temperatures a uniform chemisorbed oxygen layer with a different spectroscopic signature is formed.

\section{Acknowledgments}

This work was supported by EPSRC (through grant No EP/F02116X/1). The authors would like to thank the Diamond staff for their support during beamtime.

[1] E. Bauer, Surf. Rev. Lett. 5, 1275 (1998).

[2] E. Bauer, J. Electron Spectr. Related Phenom. 114-116, 975 (2001).

[3] H. Matsuyama, C. Haginoya, and K. Koike, Phys. Rev. Lett. 85, 646 (2000).

[4] H. Ohldag, A. Scholl, F. Nolting, S. Anders, F. U. Hillebrecht, and J. Stöhr, Phys. Rev. Lett. 86, 2878 (2001).

[5] J. G. Chen, Surf. Sci. Rep. 30, 1 (1997).

[6] J. C. de Jesús, J. Carrazza, P. Pereira, and F. Zaera, Surf. Sci. 397, 34 (1998).

[7] S. A. Chambers, Surf. Sci. Rep. 39, 105 (2000).

[8] B. P. Payne, A. P. Grosvenor, M. C. Biesinger, B. A. Kobe, and N. S. McIntyre, Surf. Interf. Analysis 39, 582 (2007). 
[9] P. H. Holloway and J. B. Hudson, Surf. Sci. 43, 123 (1974).

[10] P. H. Holloway and J. B. Hudson, Surf. Sci. 43, 141 (1974).

[11] N. Cabrera and N. F. Mott, Rep. Prog. Phys. 12, 163 (1948-1949).

[12] G. T. Tyuliev and K. L. Kostov, Phys. Rev. B 60, 2900 (1999).

[13] R. Domnick, G. Held, P. Witte, and H.-P. Steinrück, J. Chem. Phys. 115, 1902 (2001).

[14] M. Bäumer, D. Cappus, H. Kuhlenbeck, H.-J. Freund, G. Wilhelmi, A. Brodde, and H. Neddermeyer, Surf. Sci. 253, 116 (1991).

[15] E. Kopatzki and R. J. Behm, Phys. Rev. Lett. 74, 1399 (1995).

[16] S. Hildebrandt, C. Hagendorf, T. Doege, C. Jeckstiess, R. Kulla, and H. Neddermeyer, J. Vac. Sci. Technol. A 18, 1010 (2000).

[17] J. G. Chen, D. A. Fisher, J. H. Hardenbergh, and R. B. Hall, Surf. Sci. 279, 13 (1992).

[18] M. D. v. Przychowski, G. K. L. Marx, G. H. Fecher, and G. Schönhense, Surf. Sci. 549, 37 (2004).

[19] D. Norman, J. Stöhr, R. Jaeger, P. J. Durham, and J. B. Pendry, Phys. Rev. Lett. 51, 2052 (1983).

[20] M. Pedio, J. C. Fuggle, J. Somers, E. Umbach, J. Haase, T. Lindner, U. Höfer, M. Grioni, F. M. F. de Groot, B. Hillert, et al., Phys. Rev. B 40, 7924 (1989).

[21] M. Pedio, L. Becker, B. Hillert, S. D’Addato, and J. Haase, Phys. Rev. B 41, 7462 (1990).

[22] J. G. Chen, B. D. Vries, J. Lewandowski, and R. B. Hall, Catal. Lett. 23, 25 (1994).

[23] W.-D. Wang, N. J. Wu, and P. A. Thiel, J. Chem. Phys. 92, 2025 (1990). 


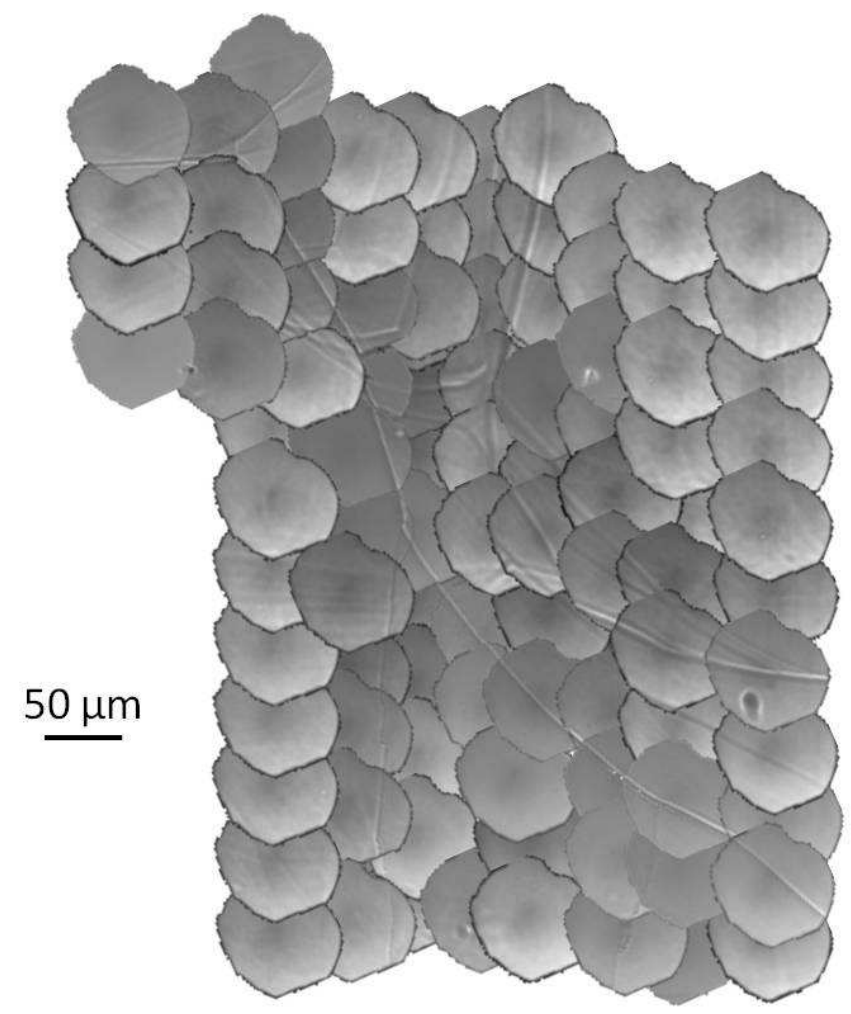

(a)

(b)

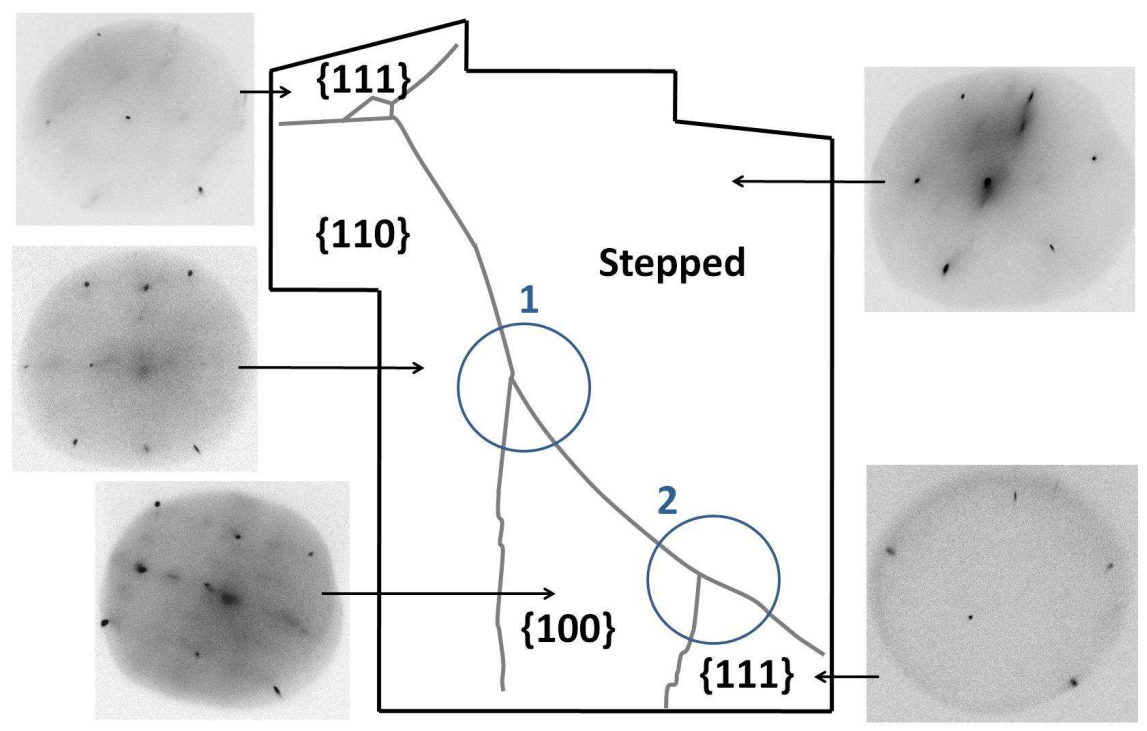

FIG. 1: (a) Surface map (area $500 \times 750 \mu \mathrm{m}^{2}$ ) compiled from LEEM (MEM) images of $80 \mu \mathrm{m}$ field of view showing five adjacent facets. (The distorted image boundaries are due to the profile of the electron beam.) The boundaries between the facets are indicated in the schematic drawing in the center (b); the additional lines seen in the map of (a) on the stepped facet in are scratch marks; micro-spot LEED patterns of each facet are also shown in (b). 


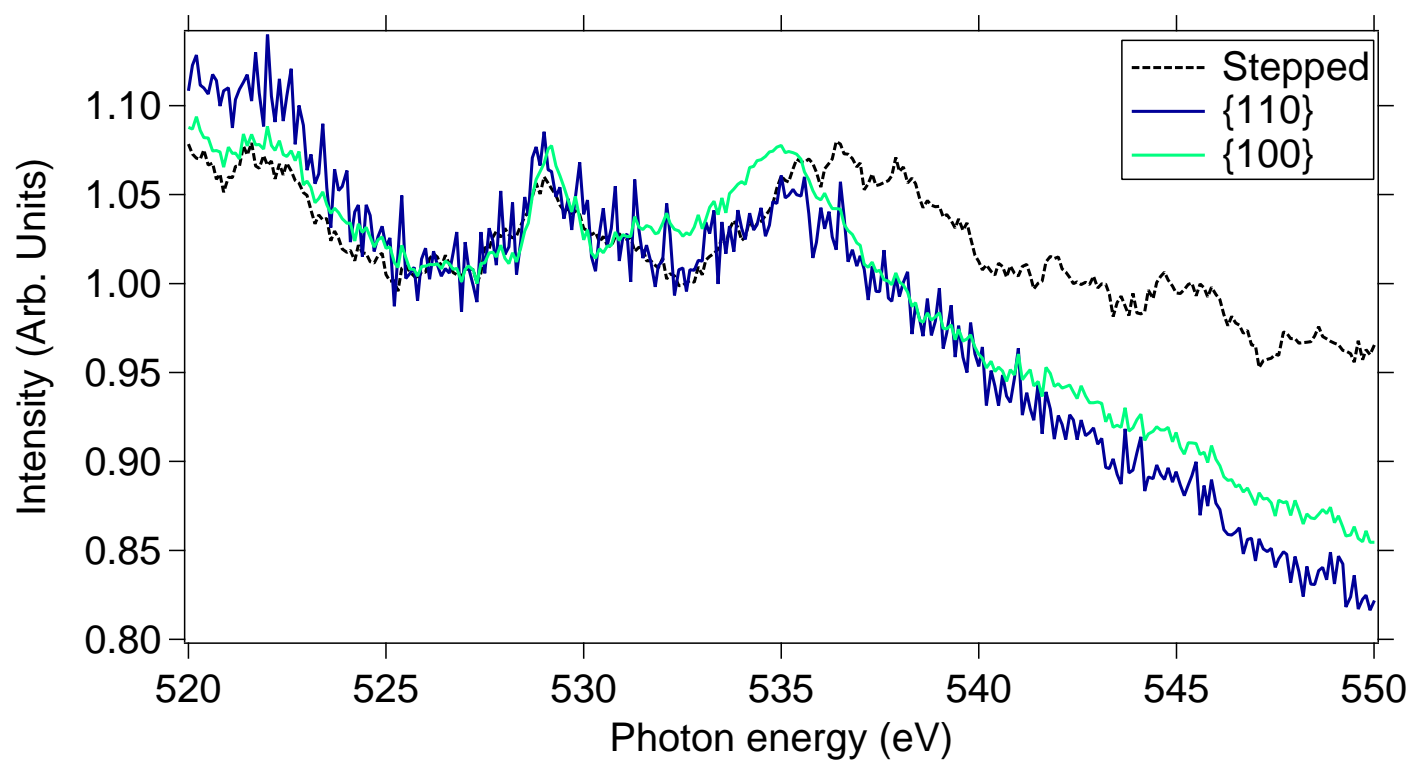

(a)

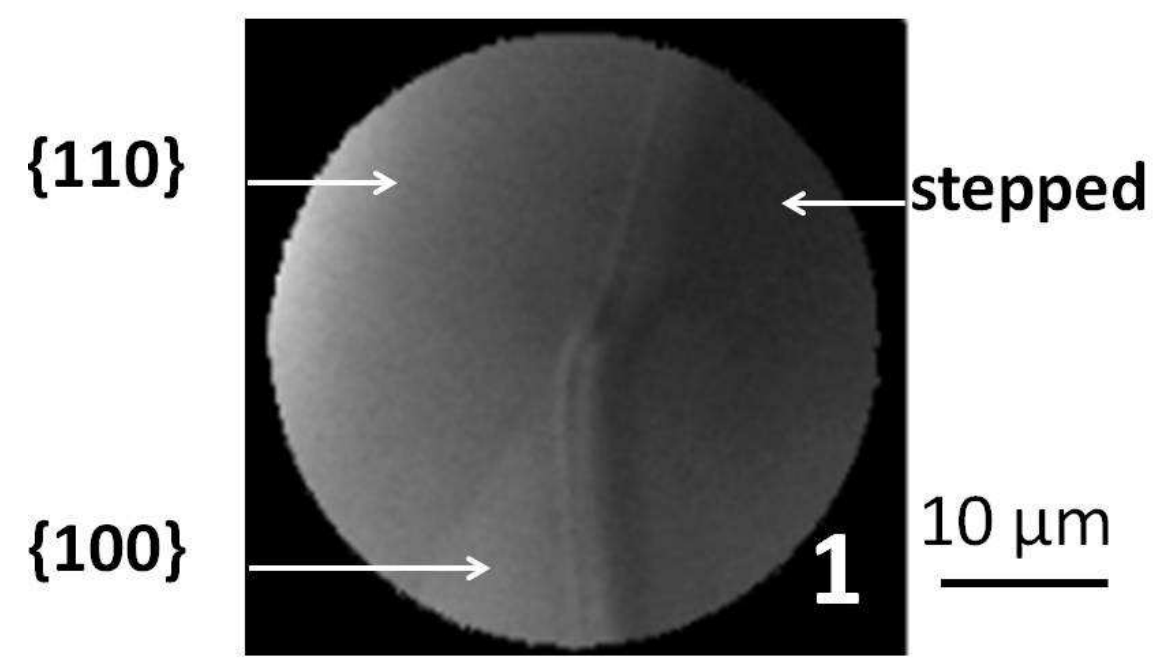

(b)

FIG. 2: (color online) (a) NEXAFS spectra from the three facets observed in region 1 after exposure to $20 \mathrm{~L}$ of oxygen at $373 \mathrm{~K}$; (b) X-PEEM image of region 1 (photon energy $529 \mathrm{eV}$ ). 


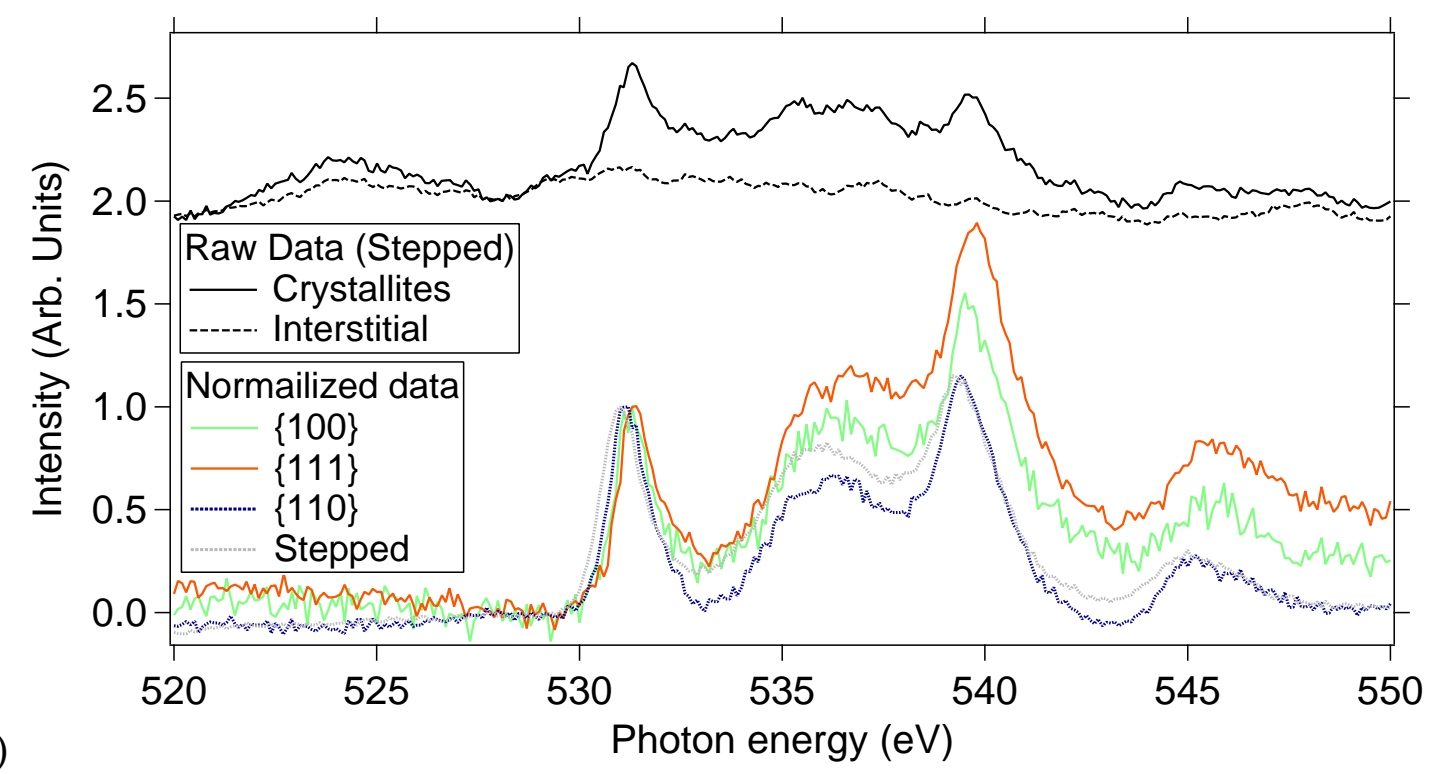

(a)
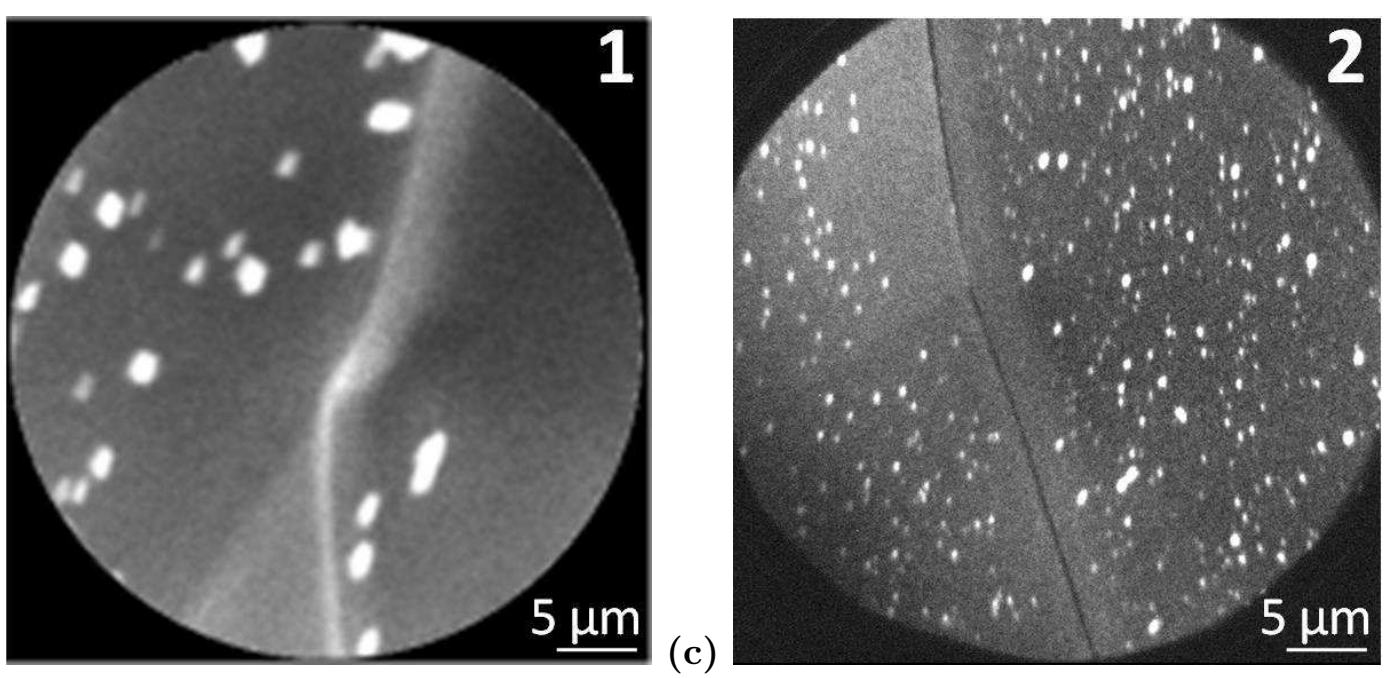

FIG. 3: (color online) (a) Normalized NEXAFS spectra from four facets of the polycrystalline Ni surface and raw NEXAFS spectra from a stepped surface after exposure to $30 \mathrm{~L}$ of oxygen at 673 K. X-PEEM images of regions 1 (b) and 2 (c) at photon energy $539.5 \mathrm{eV}$. 


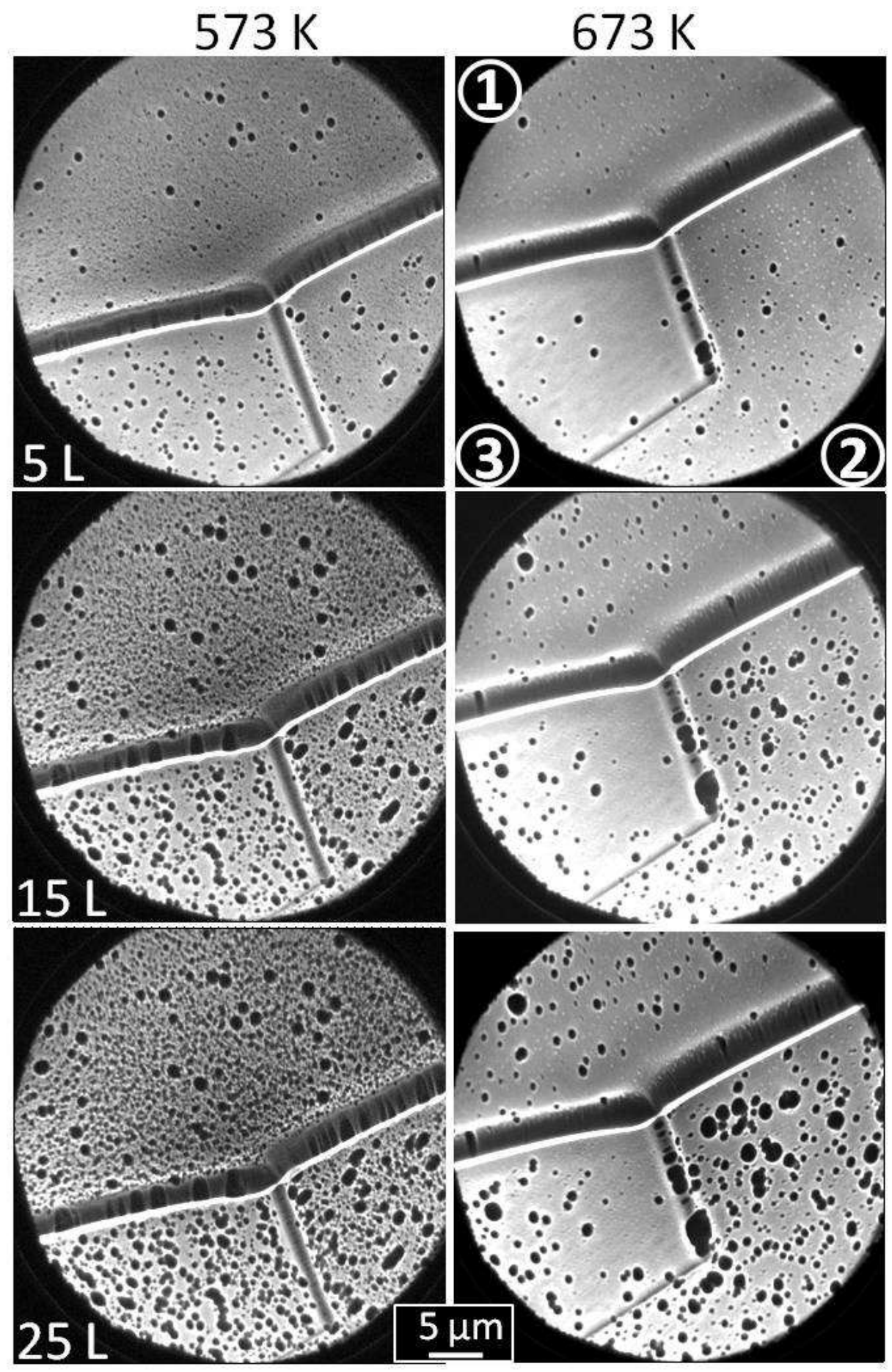

FIG. 4: LEEM images (MEM mode) recorded during the oxidation of polycrystalline $\mathrm{Ni}$ at $1 \times 10^{-8}$ mbar of oxygen. Left column: exposure at $573 \mathrm{~K}$ to 5,15 , and $25 \mathrm{~L}$; right column: exposure at g73 $\mathrm{K}$ to 5,15 , and $25 \mathrm{~L}$. The region shown here is outside the area mapped in Figure 1; the orientations of the three facets (1), (2), (3), indicated in the top right image, have not been identified by micro-spot LEED. 